\title{
Antidiabetic and Antioxidant Activities of Decoctions of Coccinia grandis Linn. and Centella asiatica (L.) on Alloxan-induced Diabetic rats
}

\author{
Md. Siddiqul Islam", Salma Parvin", Md. Nasir Uddin ${ }^{1}$ and Md. Abdul Mazid² \\ Department of Pharmacy, Manarat International University, Dhaka, Bangladesh \\ ${ }^{2}$ Department of Pharmaceutical Chemistry, Faculty of Pharmacy, University of Dhaka, Dhaka-1000, Bangladesh
}

\begin{abstract}
The decoctions of Coccinea grandis (L.) and Centella asiatica (L.) leaves were evaluated for their antidiabetic and antioxidant potentials in alloxan-induced rat model and by DPPH free radical scavenging assay, respectively. Graded doses of the decoctions administered to normal and experimental diabetic rats for two weeks showed significant reduction in fasting blood glucose levels in the normal as well as in treated diabetic animals. The experiment showed $188.42 \pm 1.2 \mathrm{mg} / \mathrm{dl}$ glucose and $117.78 \pm 11.2 \mathrm{mg} / \mathrm{dl}$ cholesterol levels for $C$. grandis, while $187.23 \pm 0.8 \mathrm{mg} / \mathrm{dl}$ glucose and $116.14 \pm 1.5 \mathrm{mg} / \mathrm{dl}$ cholesterol for $C$. asiatica. Although, the decoctions produced significant effect on serum urea level, the total protein and liver enzymes (SGOT and SGPT) were found to be normal. Acute toxicity studies showed that both the decoctions were safe at 2-fold high dose when compared with the commonly used antidiabetic dose. Total phenolic contents in decoctions were found to be $12.45 \pm 0.52$ and $8.32 \pm 0.31$ for $C$. grandis and $C$. asiatica, respectively while DPPH free radical scavenging assay showed the $\mathrm{IC}_{50}$ values of $0.14 \pm 0.001$ for C. grandis and $0.17 \pm 0.001$ for $C$. asiatica. Our current studies for the first time, justified the use of decoctions of the leaves of $C$. grandis and $C$. asiatica for treating diabeties, hyperlipaedemia and atherogenic lesion in the indigenous system of medicine.
\end{abstract}

Key words: Antidiabetic activity, serum cholesterol, antioxidant activities, C. grandis, C. asiatica.

\section{Introduction}

Dibetes mellitus (DM) is a metabolic disorder that affects carbohydrate, fat and protein metabolism. Globally, as of 2010, an estimated 285 million people had diabetes, with type 2 making up about $90 \%$ of the cases. In 2013, according to International Diabetes Federation, an estimated 381 million people had diabetes (Wild et al., 2004). The oral antihyperglycemic agents currently used in clinical practice have characteristic profiles of serious side effects (Pickup et al, 1991). This leads to increasing demand for herbal products with antidiabetic activity and less side effects (Vetrichelvan et al., 2002). On the other hand, the search for naturally occurring antioxidants has been a demand of time in view to avoid the carcinogenic effect of synthetic antioxidants. Antioxidants inhibit the oxidation of fats and other bioactive lipids of our body and prevent diseases such as cancer, coronary heart disease, etc (Diaz et al., 1997).
C. grandis L. (Family: Cucurbitaceae, Bengli name: Telakucha, Synonyms: Hydrocotyle asiatica L., Trisanthus cochinchinensis Lour.) is an important herb having a lot of disease alleviating values like antibacterial and antifungal (Bhattacharya et al., 2010), antioxidant (Deshpande et al., 2011), hypoglycemic (Manish et al., 2010) activities when different solvent extracts were used (Pekamwar et al., 2013). It has been used in ayurvedic medicine to treat diabetes from ancient times (Munasinghe et al., 2011). It also proved to have antipyretic (Aggarwal et al., 2011) and anti inflammatory (Deshpande et al., 2011) effects on different animal models. On the other hand, C. asiatica L. (Family: Umbelliferare, Bengali name: Thankuni, Synonyms: $C$. cordifolia, $C$. indica) is another important medicinal herb used for various diseases and also used in Indian Ayurvedic medicine as a nerve tonic (Singh et al., 2008). It has been known for many years in treating all kind of diseases such as gastrointestinal disease, gastric ulcer, asthma, wound,

Correspondence to: Md. Abdul Mazid, Tel.: +880-2-9661920, Ext. 8131/4364; E-mail: ma.mazid@ du.ac.bd 
anxiety and eczema (Chen et al., 2006; Wijeweera et al., 2006). The use of Centella in food and beverages has increased over the years basically due to its health benefits such as antioxidant (Hamid et al., 2002; Ullah et al., 2009), as anti-inflammatory (Duke, 2001), wound healing (Kimura et al., 2008), memory enhancing (Subathra et al., 2005) properties and many others. The potential of $C$. asiatica $\mathrm{L}$. as an alternative natural antioxidant of plant origin and its protection against age-related changes in brain antioxidant defense system, have notably increased in recent years (Subathra et al., 2005). Free radicals have been claimed to play an important role in ageing process and capable of damaging many cellular components. Various compounds like triterpenoids (James and Dubery, 2009), asiaticoside, asiatic acid which were found to have anticancer effect (Hsu et al., 2005).

Though different organic or aqueous soluble extracts of both herbs have been previously reported to have antidiabetic effect (Mustaffa et al., 2011; Attanayake et al., 2013) but no study have yet been done by using hot water extract of the leaves of both the plants. Since traditional healers usually prescribe the herbs to the patients to be taken with water, we for the first time, studied the antidiabetic activity of the decoctions of $C$. grandis (L.) and C. asiatica (L.) leaves on experimental diabetic rats. We have also evaluated the antioxidant activity and acute toxicities of the decoctions.

\section{Materials and Methods}

Plant material and decoction preparation: The leaves of Coccinia grandis L. and Centella asiatica L. were collected in December, 2012 from Jessore and Savar, Dhaka, respectively and authenticated by Bangladesh National Herbarium. The leaves were dried under shade and $100 \mathrm{~g}$ each of $C$. grandis and C. asiatica powdered leaves were boiled in one liter water for 10 minutes. This was allowed to stand for $30 \mathrm{~min}$ and filtered through clean cloth and then Whatman no. 1 filter paper. The filtrates so obtained were further reduced under vacuum to $100 \mathrm{ml}$ for both the plants. Such procedure resulted in a decoction with a higher concentration than that produced by the method described by Teixeira et al. (1990). Both the concentrated decoctions contained $1 \mathrm{~g}$ equivalent powder per ml.
Test animals and treatment plan: Swiss Albino rats of Wister strain of either sex weighing 180-200 g used as test animals in the study and treatment plan were obtained from ICDDR, B, Dhaka. They were individually housed in polypropylene cages in well-ventilated rooms, under hygienic conditions and were given water and rat pellet feed. Rats were divided into five groups (Each group contained 5 rats): Group I received normal diet and served as normal control. Group II consists of alloxan induced rats received normal diet and serving as diabetic control. Group III consists of alloxan-induced rats received Glibenclamide (synthetic antidiabetic drug) at $0.5 \mathrm{mg} / \mathrm{kg}$ body weight once a day orally for 14 days (Das et al., 2011). While, group IV and group V consist of alloxaninduced rats received concentrated decoction of $C$. grandis and $C$. asiatica leaves at a dose of $3 \mathrm{ml} / \mathrm{kg}$ body weight) once a day orally for 14 days each, respectively.

Alloxan monohydrate solution of $10 \mathrm{mg} / \mathrm{ml}$ was prepared in citrate buffer $(0.1 \mathrm{M} \mathrm{pH} 4.5) \mathrm{kept}$ in ice and was administered to the rats within $5 \mathrm{~min}$ at a dose of 50 $\mathrm{mg} / \mathrm{kg}$ body weight intraperitonially. After $48 \mathrm{~h}$ of alloxan administration, rats with moderate diabetes having glycosuria and hyperglycemia were taken for the experiment.

Collection of blood sample and analysis: Blood samples were collected through the tail vein just prior to and on days 14 after drug administration. The blood glucose level was estimated by using glucometer (Bioland-423, Germany) (Khan et al., 2008). Urea, cholesterol, serum glutamate oxygenase transaminase (SGOT)/ Aspartate transaminase (AST) and serum glutamate pyruvate transaminase (SGPT)/ Alanine transaminase (ALT) were determined by UV spectrophotometric method (Shimadzu UV-1200, Tokyo, Japan), using wet reagent diagnostic kits according to manufacturer's protocol for all the samples (Khan et al., 2010).

Total phenolics content and free radical scavenging assay: Total phenolic contents in the decoctions of the leaves of $C$. grandis and $C$. asiatica were measured by using Folin-Ciocalteu reagent as described before (Amin et al., 2004) using $0.25 \mathrm{ml}$ decoction for each reaction. Gallic acid $(0.01-0.05 \mathrm{mg} / \mathrm{ml})$ was used as standard.

The DPPH (1,1-diphenyl-2-picrylhydrazyl) free radical scavenging activity was assayed using the method 
described previously (Chan et al., 2006) using $0 \mathrm{ml}, 0.25$ $\mathrm{ml}$ and $0.5 \mathrm{ml}$ decoctions in each test tubes for reactions.

The scavenging activities of the decoctions were calculated using the following equation:

Scavenging activity $(\%)=(1-$ Absorbance of sample/ Absorbance of control) x 100

DPPH free radical scavenging activities were expressed as $\mathrm{IC}_{50}$ values.

Acute toxicity study: Acute toxicity studies of decoctions of both $C$. grandis and $C$. asiatica were also assessed to evaluate the safety by following the Organization for Economic Cooperation and Development (OCED) guidelines 425, fixed dose procedure. For screening the toxicity, healthy adult rats of either sex, starved overnight, were divided into five groups (each group containing five rats); control group was fed with hot water whereas the other groups were treated with concentrated decoction of $C$. grandis and $C$. asiatica at a dose of $3 \mathrm{ml}$ and $6 \mathrm{ml}$ (1 gm equivalent dry leaves powder/ml) per kg of body weight, orally. The treated rats were observed continuously for $2 \mathrm{~h}$ for behavioral, neurological and antunomic profiles. The lethality of the rats was observed after a period of $24 \mathrm{~h}$ and $72 \mathrm{~h}$ (Ghosh, 1984; Turner, 1965).

Statistical analysis: Experiments were carried out in triplicates and data were expressed as Mean \pm SEM (standard error of mean). Unpaired $t$-test was carried out for statistical comparison. Statistical significance was indicated by $\mathrm{p}<0.05$ in all cases.

\section{Results and Discussion}

The hot water extracts or decoctions of the dried leaves of $C$. grandis and $C$. asiatica produced significant changes in the alloxan induced diabetic rats (Table 1). The decoction of both the plants reduced glucose level considerably in comparison to treatment of the diabetic rats and the results were comparable with that of Glibenclamide $(10 \mathrm{mg} / \mathrm{kg})$. The prolonged treatment also reduced urea, protein and total cholesterol (Tables 1 and 2) level in comparison to diabetic rats.

Table 1. Glaucose and cholesterol content of serum in control and experimental rats.

\begin{tabular}{llcc}
\hline Group & Treatment & Glucose $(\mathrm{mg} / \mathrm{dl})$ & Cholesterol $(\mathrm{mg} / \mathrm{dl})$ \\
\hline Group-1 & Control & $118.6 \pm 1.4$ & $124.7 \pm 1.5$ \\
Group-II & Diabetic control & $248.1 \pm 1.6$ & $238.1 \pm 1.2$ \\
Group-III & Diabetic + Glibenclamide & $114.11 \pm 1.7^{*}$ & $118.08 \pm 1.8$ \\
Group-IV & Diabetic + C. grandis extract & $188.42 \pm 1.2^{* *}$ & $127.78 \pm 11.2$ \\
Group-V & Non diabetic + C. grandis extract & $116.2 \pm 1.5$ & $119.8 \pm 1.7$ \\
Group-VI & Diabetic + C. asiatica extract & $187.23 \pm 0.8^{* *}$ & $126.14 \pm 1.5$ \\
Group-VII & Non diabetic + C. asiatica extract & $115.7 \pm 1.3$ & $120.2 \pm 1.4$ \\
\hline
\end{tabular}

Values are expressed as Mean $\pm \operatorname{SEM}(\mathrm{n}=5)$. **:p<0.05 significant compared to diabetic rats

The blood glucose data obtained clearly indicate significant antihyperglycemic effect in alloxan induced diabetic rats. That means, both the herbs may potentiate pancreatic secretion or may reuptake glucose. Hypercholesterolemia, hypertriglyceridemia and hyperuricemia have been reported to occur in alloxaninduced diabetic rats (Resmi et al., 2001).

Increase in glycogen in liver can be brought about by an increase in glycogenesis and/or decrease in glycogenolysis. Therefore, decoctions of both the plants could have stimulated the process. Slight increase in total protein (Table 2) may be due to changes in circulating amino acids levels, hepatic amino acids uptake and muscle output of amino acid concentrations (Felig et al., 1977). The non-protein nitrogenous compound, urea and the liver enzymes level such as SGPT and SGOT were found to be increased in alloxan-induced diabetic rats. The serum level of urea and liver enzymes came to normal upon treatment with the decoctions of $C$. grandis and $C$. asiatica, remarkably. Our results support that the previous report that transaminase activity is increased in the serum of a diabetic rat which is active in absence of insulin due to the availability of amino acids in the blood (Ghosh et al., 2004). While on the other hand, we also found that the total cholesterol level as increased in diabetic rats was also significantly reduced upon treatment with the decoctions 
of both plants. These might be due to increased uptake of glucose by peripheral tissues or by depressed activities of lipogenic and cholesterogenic enzymes (Chi, 1982; Yeh, 2001).

Acute toxicological studies using 2-fold higher doses of the decoctions of both plants than that of the doses used in antidiabetic studies did not cause any beharioral, neurolocgical or antonomic changes (Table 3). There was no mortality or morbidity observed after three days of treatment by the decoctions. Morphological characteristic

Table 2. Concentration of urea, total protein, SGOT and SGPT in serum of control and experimental rats.

\begin{tabular}{llcccc}
\hline Group & Treatment & $\begin{array}{c}\text { Urea } \\
(\mathrm{mg} / \mathrm{dl})\end{array}$ & $\begin{array}{c}\text { SGOT } \\
(\mathrm{U} / \mathrm{L})\end{array}$ & $\begin{array}{c}\text { SGPT } \\
(\mathrm{U} / \mathrm{L})\end{array}$ & $\begin{array}{c}\text { Total } \\
\text { protein }\end{array}$ \\
\hline Group-I & Control & $47.1 \pm 0.31$ & $24.1 \pm 1.3$ & $26.1 \pm 1.4$ & $7.9 \pm 0.31$ \\
Group-II & Diabetic control & $61.7 \pm 2.1$ & $27.4 \pm 1.2$ & $27.9 \pm 1.8$ & $6.1 \pm 0.21$ \\
Group-III & Diabetic + Glibenclamide & $53.6 \pm 1.9$ & $30.9 \pm 2.1$ & $34.2 \pm 11.5$ & $3.8 \pm 0.8$ \\
Group-IV & Diabetic + C. grandis decoction & $52.1 \pm 1.4$ & $52.1 \pm 1.4$ & $31.1 \pm 1.6$ & $8.4 \pm 0.32$ \\
Group-V & Non diabetic + C. grandis decoction & $48.1 \pm 1.5$ & $25.7 \pm 1.4$ & $27.8 \pm 1.1$ & $8.5 \pm 1.4$ \\
Group-VI & Diabetic + C. asiatica decoction & $51.9 \pm 1.6$ & $28.2 \pm 2.8$ & $30.2 \pm 1.3$ & $8.1 \pm 0.41$ \\
Group-VII & Non diabetic + C. asiatica decoction & $47.7 \pm 1.3$ & $26.4 \pm 1.1$ & $28.1 \pm 1.5$ & $8.4 \pm 1.0$ \\
\hline
\end{tabular}

Values are taken as a mean of five individuals and expressed as Mean \pm SEM.

Table 3. Toxicity study data of $C$. grandis and $C$. asiatica leaves on rat model.

\begin{tabular}{|c|c|c|c|c|}
\hline \multirow[t]{3}{*}{ Parameters observed } & \multicolumn{4}{|c|}{ Treatment } \\
\hline & \multicolumn{2}{|c|}{ C. grandis } & \multicolumn{2}{|c|}{ C. asiatica } \\
\hline & $3 \mathrm{ml} / \mathrm{kg}$ & $6 \mathrm{ml} / \mathrm{kg}$ & $3 \mathrm{ml} / \mathrm{kg}$ & $6 \mathrm{ml} / \mathrm{kg}$ \\
\hline \multicolumn{5}{|l|}{ Stimulation } \\
\hline Respiration & Normal & Normal & Normal & Normal \\
\hline Agitation & Normal & Normal & Normal & Normal \\
\hline Aggressiveness & Nil & Nil & Nil & Nil \\
\hline Fur erection & Normal & Normal & Normal & Normal \\
\hline Exophthalmia & Nil & Nil & Nil & Nil \\
\hline Movement & Normal & Normal & Normal & Normal \\
\hline Jaw movement & Normal & Normal & Normal & Normal \\
\hline Convulsion & Nil & Nil & Nil & Nil \\
\hline Tremors & Nil & Nil & Nil & Nil \\
\hline Tail erection & Normal & Normal & Normal & Normal \\
\hline Irritability & Nil & Nil & Nil & Nil \\
\hline \multicolumn{5}{|l|}{ Depressor } \\
\hline Static position & Normal & Normal & Normal & Normal \\
\hline Dyspnea & Nil & Nil & Nil & Nil \\
\hline Sleepiness & Nil & Nil & Nil & Nil \\
\hline Prostration & Normal & Normal & Normal & Normal \\
\hline Altered stride & Nil & Nil & Nil & Nil \\
\hline Eye dullness & Nil & Nil & Nil & Nil \\
\hline \multicolumn{5}{|l|}{ Others } \\
\hline Fecal production & Normal & Normal & Normal & Normal \\
\hline Diuresis & Normal & Normal & Normal & Increased \\
\hline Spasms & Nil & Nil & Nil & Nil \\
\hline Diarrhea & Nil & Nil & Nil & Nil \\
\hline Regurgitation & Nil & Nil & Nil & Nil \\
\hline Pallor & Nil & Nil & Nil & Nil \\
\hline Abdominal distension & Nil & Nil & Nil & Nil \\
\hline Spasticity & Nil & Nil & Nil & Nil \\
\hline Cyanosis & Nil & Nil & Nil & Nil \\
\hline Hemorrhagic spots & Nil & Nil & Nil & Nil \\
\hline
\end{tabular}

Nil: No sign was observed. 
(fur, skin, eyes, and nose) appeared to be normal. No tremors, convulsion, salivation, diarrhea, lethargy or unusual behavior were observed (Table 3). The acute toxicity study indicated that treatment with the decoctions at the selected doses was well tolerated by the test animals, suggesting its safety for further investigations.

Further attempt to the measurement of the total phenolic contents showed that the decoction of $C$. grandis and $C$. asiatica contained $12.45 \pm 0.52$ and $8.32 \pm 0.31 \mathrm{mg}$ of $\mathrm{GAE} / \mathrm{gm}$ of dry powder of phenolic compounds, respectively, while in vitro DPPH free radical scavenging assay revealed the antioxidant activities with $\mathrm{EC}_{50}$ values of $0.14 \pm 0.001$ and $0.17 \pm 0.001$ for the decoction $C$. grandis and C. asiatica, respectively (Table 4). These data further provided primary evidence of the usefulness of decoction of leaves of both plants in the prevention of atherogenic lesion in addition to their uses as antidiabetic agents.

Table 4. Total phenolic content and $\mathrm{IC}_{50}$ values (in DPPH assay) of the decoctions of $C$. grandis and $C$. asiatica.

\begin{tabular}{lcc}
\hline Samples & $\begin{array}{c}\text { Total phenolic } \\
\text { content } \\
\text { (mg of GAE/gm } \\
\text { of dry powder) }\end{array}$ & $\begin{array}{c}\text { Free radical } \\
\text { scavenging activity } \\
\text { IC50 }(\mathrm{mg} / \mathrm{ml})\end{array}$ \\
\hline C. grandis & $12.45 \pm 0.52$ & $0.14 \pm 0.001$ \\
C. asiatica & $8.32 \pm 0.31$ & $0.17 \pm 0.001$ \\
$\begin{array}{l}\text { Ascorbic acid } \\
\text { (Standard) }\end{array}$ & - & $0.004 \pm 0.001$ \\
Trolox & - & $0.003 \pm 0.001$ \\
(Standard) & - & \\
\hline
\end{tabular}

\section{Conclusion}

In conclusion, the decoction of $C$. grandis and $C$. asiatica leaves showed significant anti-diabetic activity. For the first time we proved that the decoctions of the leaves of both the plants may also be used for the treatment of high cholesterol level. During the experiment, no acute toxicities were observed, which revealed their safety in animal model. Moreover, our preliminary measurement of phenolic contents also showed that both the decoctions of $C$. grandis and $C$. asiatica contained moderate amount of phenolics that could inhibit free radical related cellular damage. Thus, the decoctions might also be useful to prevent atherogenic disorders.

\section{References}

Aggarwal, A.S., Suralkar, U.R., Chaudhari, S.G., Deshpande, S.V., Garud, A.A. and Talele, S.G. 2011. Analgesic and antipyretic activity of methanolic extract of Coccinia grandis L. Leaves in experimental animals. Res. J. Pharm. Biol. Chem. Sci. 2, 175-182.

Amin, I., Zamaliah, M.M. and Chin, W.F. 2004. Total antioxidant activity and phenolic content in selected vegetables. Food Chemistry. 87, 581-586.

Attanayake, A.P., Jayatilaka K.A.P.W., Pathirana, C. and Mudduwa, L.K.B. 2013. Efficacy and toxicological evaluation of Coccinia grandis (Cucurbitaceae) extract in male Wistar rats. Asian Pac. J. Trop. Dis. 3, 460-466.

Bhattacharya, B., Samanta, M., Pal, P., Chakraborty, S. and Samanta, A., 2010. In vitro evaluation of antifungal and antibacterial activities of the plant Coccinia grandis (L.) Voigt. (Family-Cucurbitaceae). J. Phytology 2, 52-57.

Chen, S.W., Wang, W.J., Li, W.J., Wang, R., Li, Y.L., Huang, Y.N. and Liang, X. 2006. Anxiolytic-like effect of asiaticoside in mice. Pharmacol. Biochem. Behav. 85, 339344.

Chi, M. S. 1982. Effects of garlic products on lipid metabolism in cholesterol-fed rats. Proc. Soc. Exp. Biol. Med. 171, 174178.

Das, S., Bhattacharya. S., Prasanna, A., Suresh, K.R.B., Pramanik, G., Haldar, P.K. 2011. Preclinical evaluation of antihyperglycemic activity of Clerodendron infortunatum leaf against streptozotocin-induced diabetic rats. Diabetes Ther. 2, 92-100.

Deshpande, S.V., Patil, M.J., Daswadkar, S.C., Suralkar, U., Agarwal, A. 2011. A study on anti-inflammatory activity of the leaf and stem extract of Coccinia grandis. Int. J. Appl. Biol. Pharmaceut. Technol. 2, 247-250.

Diaz, M.N., Frei, B., Vita, J.A., Keaney, J.F.Jr. 1997. Antioxidants and atherosclerotic heart disease. New Engl. J. Med. 337,408-416.

Duke, J. A. 2001. Handbook of Medicinal Herbs. $1^{\text {st }}$ edn, New York: CRC Press.

Felig, P., Wahren, J., Sherwin, R. and Palaiologos, G. 1977. Amino acid and protein metabolism in diabetes mellitus. Arch. Intern. Med. 137, 507-513.

Ghosh, M.N. 1984. Toxicity studies, In: Fundamentals of Experimental Pharmacology. Scientific Book Agency. Calcutta, pp. 153-158.

Ghosh, R., Sharatohandra, K.H., Rita, S. and Thokchom, I.S. 2004. Hypoglycaemic activity of Ficus Hispida (bark) in normal and diabetic albino rats. Indian J. Pharmacol. 36, 222-225. 
Hamid, A. A, Md Shah, Z., Muse, R. and Mohamed, S. 2002. Characterisation of antioxidative of Centella asiatica (L). Food Chem. 77, 465-469.

Hsu, Y.L., Kuo, P.L., Lin, L.T. and Lin, C.C. 2005. Asiatic acid, a triterpene, induces apoptosis and cell cycle arrest through activation of extracellular signal-regulated kinase and p38 mitogen-activated protein kinase pathways in human breast cancer cells. J. Pharmacol. Exp. Ther. 313, 333-344.

James, J.T. and Dubery, I.A. 2009. Pentacyclic Triterpenoids from the Medicinal Herb, Centella asiatica (L.). Molecules 14, 3922-3941.

Khan, M.R.I., Islam M.A., Hossain, M.S., Asadujjaman, M., Wahed, M.I.I., Rahman, B.M., Anisuzzaman, A.S.M, Shaheen, S.M. and Ahmed, M. 2010. Antidiabetic effects of the different fractions of ethanolic extracts of Ocimum sanctum in normal and alloxan induced diabetic rats. J. Sci. Res. 2, 158-168.

Kimura, Y., Sumiyoshi, M., Samukawa, K., Satake, N. and Sakanaka, M. 2008. Facilitating action of asiaticoside at low doses on burn wound repair and its mechanism. European $J$. Pharmacol. 584, 415-421.

Manish, G., Jana, G.K., Jha, A.K. and Mishra U. 2010. Pharmacognostic and antihyperglycemic study on Coccinia indica. Int. J. Phytomed. 2, 36-40.

Mustaffa, F., Indurkar, J., Ali, N.I.M., Hanapi, A. Shah, M., Ismail, S. and Mansor, S.M.A. 2011. review of malaysian medicinal plants with potential antidiabetic activity. $J$. Pharm. Res. 4, 4217-4224.

Pekamwar, S.S., Kalyankar T.M., and Kokate S.S. 2013. Pharmacological activities of Coccinia grandis: review. $J$. Appl. Pharmaceut. Sci. 3, 114-119.
Pickup, J. and Williams, G. 1991. Text Book of Diabetes, Black Well, Oxford, pp. 467-469.

Resmi, C. R., Aneez, F., Sinilal, B., Latha, M. S. 2001. Antidiabetic effect of a herbal drug in alloxan-diabetic rats. Indian Drugs 38, 319-322.

Singh, R. H., Narsimhamurthy, K. and Singh G. 2008. Neuronutrient impact of Ayurvedic Rasayana therapy in brain aging. Biogerontology 9, 369-374.

Subathra, M., Shila, S., Devi, M. A. and Panneerselvam, C. 2005. Emerging role of Centella asiatica in improving agerelated neurological antioxidant status. Experimental Gerontology. 40, 707-715.

Turner, M.A. 1965. In: Screening Methods in Pharmacology. Academic Press, New York, p. 26.

Ullah, M.O., Sultana, S., Haque, A. and Tasmin, S. 2009. Antimicrobial, cytotoxic and antioxidant of Centella asiatica. European J. Sci. Res. 30, 260-264.

Vetrichelvan, T., Mannippan, J., Bangaru, A. and Uma, D. 2002. Anti diabetic activity of alcoholic extract of Celosia argentea Linn Seeds in rats. Biol. Pharm. Bull. 25, 526-528.

Wijeweera, P., Arnason, J.T., Koszycki, D., and Merali, Z. 2006. Evaluation of anxiolytic properties of Gotukola - (Centella asiatica) extracts and asiaticoside in rat behavioral models. Phytomedicine 13, 668-676.

Wild, S., Roglic, G., Green, A., Sicree, R. and King, H. 2004. Global prevalence of diabetes: estimates for the year 2000 and projections for 2030. Diabetes Care. 27, 1047-53.

Yeh, Y.Y. and Liu, L. 2001. Cholesterol-lowering effect of garlic extracts and organosulfur compounds: human and animal studies. J. Nutr. 131, 989S-993S. 